\title{
En busca de la calidad educativa a partir de los procesos de lectura y escritura
}

\author{
Mireya Cisneros E. \\ Violeta Vega P. \\ Universidad Tecnológica de Pereira (UTP), Vicerrectoría de \\ Investigaciones, Innovación, y Extensión, 120 pp., \\ Pereira, Risaralda, Colombia
}

Como está indicado en el título de este texto, las autoras reflexionan, en 120 páginas, sobre la base de un trabajo de investigación académica llevado a cabo dentro del equipo Grupo de Estudios del Habla y de la Comunicación en la universidad mencionada, y que gira en torno a tres ejes temáticos. Podemos sintetizarlos como sigue: la calidad educativa y la alfabetización académica, sus dificultades, pertinencia, visión filosófica y social. Un segundo eje se centra en la didáctica de la lectura y la escritura a nivel académico, ello como un proceso continuo, para terminar con el desarrollo de competencias comunicativas (discursivas y textuales) y la evaluación de dicho proceso. En tercer lugar, destaca el análisis amplio y profundo de los procesos de lectura y escritura con relación a las políticas nacionales e internacionales, realidades frente a políticas existentes, así como los enfoques desde las mismas comunidades académicas. Es precisamente en este sentido donde se vislumbra con claridad la necesidad de abordar esta temática en la formación profesional a nivel de educación superior.

El término calidad es, hoy por hoy, tan recurrente que se ha convertido en el eje central de las reformas educativas en las últimas dos décadas, tanto que ya parece designar algo claramente distinguible y aceptable en este campo que no deja, simplemente, de ser una apariencia. Sin embargo, el término calidad no resulta fácil de aplicar en terreno educacional, pues su definición depende de quién es el sujeto que efectúa la demanda, y desde dónde es formulada; así, cada sector entiende el concepto de calidad en función de las distintas demandas - como dicen las autoras- que 'hace el sistema'.

Por otra parte, la búsqueda de calidad en los procesos de enseñanzaaprendizaje exige una construcción clara, colegiada y en contextos concretos, que giran alrededor de lo que designa o se pretende modelar al invocar el término; esta legítima pretensión exige también una búsqueda de sentido en los procesos que involucren las preocupaciones y 
Reseña / En Busca de la Calidad Educativa a partir de los Procesos de Lectura y Escritura / Omer Silva Villena

posibilidades de quienes laboran en dichos ambientes académicos. Es que el tema de la didáctica de la lectura y la escritura en la Educación Superior cumple un papel importante y urgente de atender, por su transversalidad en los aprendizajes académicos.

Lo anterior puede constatarse en la creciente preocupación en el medio latinoamericano en el número de investigaciones o proyectos institucionales, tendientes a promover el fortalecimiento de la lectura y la escritura, con el fin de actualizar y perfeccionar las metodologías de enseñanza, producto de reiteradas reflexiones que combinan aspectos pedagógicos y psico-lingüísticos en el desarrollo y presentación de un 'texto'. En detalle, esta publicación nos deja muy bien informados sobre lo que ocurre en la realidad de la Educación Superior Colombiana extrapolables, sin duda, a nuestro medio, con las naturales adecuaciones. Todo ello en la legítima preocupación por establecer diálogos académicos sobre alfabetización que vislumbren logros y tareas pendientes, mirando siempre hacia el desarrollo académico y personal de los estudiantes. En este sentido, las autoras plantean que gran parte de las posibilidades y los desafíos o retos de un sistema educativo, están del lado de estas orientaciones o movimientos que se pueden lograr por medio de la 'actividad discursiva y textual en la academia'. Dicho de otra manera, es posible hablar de la búsqueda de un lugar para los procesos de enseñanza, centrados en la lectura y la escritura pero, ahora, de amplia relevancia en un contexto universitario. Resulta claro, entonces, que el desarrollo de las distintas áreas del conocimiento pasa por el lenguaje, pero su transversalidad aún vemos que, en los pre-grados y postgrados, no muestra la importancia que merece. Sobre esta base, y una vez leída esta contribución de la Dra. Cisneros y Violeta Vega, cabría preguntarse si aquello que denominamos 'alfabetización académica', resulta explicable y comprensible para todos los miembros de una comunidad académica y, además, a qué estadio de destrezas comunicativas se alude con el concepto cuando se habla, investiga y discute sobre ello.

En consecuencia, no resulta ociosa una reflexión sobre lo que le corresponde a la enseñanza y el aprendizaje en el manejo de recursos lingüísticos como herramienta de aprendizajes en la universidad. Si se develan los factores influyentes en este proceso, será más fácil, entonces, la búsqueda de estrategias adecuadas a las exigencias que imponen los ambientes académicos a sus estudiantes. Este libro constituye un aporte extraordinario a estos desafíos en la búsqueda de la así llamada 'calidad académica'. Ello requiere, sin duda, trascender los enfoques, métodos y técnicas específicos en la enseñanza de una determinada disciplina. Queda claro también que, con este libro, estamos ingresando al debate

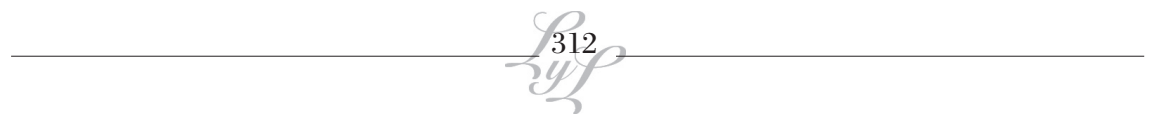


sobre la calidad de la educación a nivel terciario, desde la perspectiva de la alfabetización académica, en cuanto a que la cualificación en lectura y escritura son necesarios y de la mayor importancia para los aprendizajes, en los dominios que abarcan las distintas disciplinas en una malla curricular. Eso sí, teniendo como horizonte el pensamiento crítico y la capacidad de diálogo como metas u objetivos de toda formación académica, aspirando de esta manera a poder recuperar la tarea de enseñar a leer y escribir en una dimensión cultural, analítica y reflexiva.

Finalmente, en el capítulo sobre nuevos retos para el propósito de asumir la tarea planteada, la lectura y la escritura y, 'a manera de conclusión', estas destrezas académicas (leer y escribir) de la lengua no pueden constituir contenidos separados de sus contextos políticos y culturales, principalmente en cuanto a valores sociales al final de una carrera, como ayuda para emprender un desarrollo profesional a futuro. Sin embargo, ello pone en duda la existencia de si existen, realmente, estrategias para desarrollar estas destrezas como únicas y válidas, aplicables o transferibles a cualquier disciplina. Así, las políticas y los procesos de formación profesional, no podrían dejar de reflexionar sobre los criterios y mecanismos particulares a tener en cuenta por quienes interpretan y redactan un área específica del conocimiento, cuando se selecciona un metalenguaje con significados pertenecientes a un formato disciplinar específico. Desde luego, se hace necesaria la participación de profesionales en Ciencias del Lenguaje que acompañen a este proceso de un modo disciplinar y grupal, y no exclusivamente 'disciplinar y/o solitario', concluyen las autoras.

Aún más, esto que conocemos como sociedad del conocimiento, apenas podremos entenderla como una posibilidad que dependa de la coherencia de las acciones institucionales con las intencionalidades de las iniciativas académicas; ello para generar en estudiantes y docentes una conciencia, en relación con las razones que llevan a adscribir aquello que plantean en lo que conocemos como 'mallas curriculares' o 'planes de estudios'. Parafraseando a Paulo Freire, las autoras dejan lanzada la idea de que 'la relación entre educación y calidad puede asumirse como educación para la calidad, calidad de la educación, o educación y calidad de vida'. Ellas tienen que ser motivo de políticas y de preocupaciones al interior de las propias comunidades académicas.

Omer Silva Villena

Grupo de Estudios del Habla y de la Comunicación

Categoría Al de COLCIENCIAS de Colombia Universidad Tecnológica de Pereira, Pereira, Risaralda, (UTP)

(Investigador Externo, Chile) 